\title{
Quantity and Location Decision of Fresh Food Distribution Centers for a Supermarket Chain under Carbon Policies
}

\author{
Min Wang \\ School of Economics \\ and Management, \\ Southeast University \\ wmk111@126.com
}

\author{
Halil Ibrahim Gündüz \\ Department of Logistics, Tourism \\ and Service Management, \\ German University of \\ Technology in Sultanate of Oman \\ halil.guenduez@gutech.edu.om
}

\author{
Michael Herty \\ Institute for Geometry and \\ Applied Mathematics, \\ RWTH Aachen University \\ herty@igpm.rwth-aachen.de
}

\author{
Lindu Zhao \\ School of Economics \\ and Management, \\ Southeast University \\ ldzhao@seu.edu.cn
}

\begin{abstract}
Supermarket chains handle frequent deliveries of fresh food to the stores, which have led to the nonignorable high transportation cost. Then a question arises that is it possible to reduce cost by establishing more refrigerated distribution centers (DC)? To answer this question, on basis of data from a large supermarket chain in China, we analyze the decision making process to construct new sub DCs. A balance of the DC cost and the transportation cost is achieved to gain the optimal number and location of sub DCs. We also extend the model to situations with carbon policies (carbon tax policy and carbon cap-and-trade policy). The locations of sub DCs remain the same under carbon policies. Furthermore, a carbon tax policy does not change the number of sub DCs and only causes an increase in the total cost. Under a carbon cap-and-trade policy the optimal decision of the DC number is dependent on the carbon selling rule.

Keywords: Location decision; Distribution center; Carbon policy; Fresh food; Supermarket chain
\end{abstract}

\section{Introduction}

Fresh food distribution is vital to the operation of supermarkets. In order to guarantee food freshness, supermarket chains need to handle frequent deliveries of fresh food. In some circumstances, they even make daily distributions to gain competitive advantages. Obviously, the current situation with high-frequency distributions has led to the non-ignorable high transportation cost. Thus, it has become an urgent issue for supermarket chains to answer the question how to reduce the relevant cost. Can the goal be achieved by setting up more refrigerated distribution centers (DC)? If so, how many additional DCs should be established and where should they be located?

To gain answers to the questions, on basis of data available from a large supermarket chain in China, we analyze the decision making process to construct new refrigerated DCs. A balance of the DC cost and the transportation cost is desired. In this process, the locations of potential DCs are also provided. The Chinese supermarket chain XX (hereinafter referred to as Company $\mathrm{XX}$ ) is the largest supermarket chain in the considered province AA and it ranks top ten in retail industry nationwide. The group has 2200 stores, over 100 thousand employees and its retail scope has covered six provinces at the end of 2014. The expansion of the distribution network as part of balancing between transportation and DC costs has been a major interest of the company in recent years. So far, concerning fresh food, only a single refrigerated warehouse covering $7000 \mathrm{~m}^{2}$ is being used which is newly-built in 2015. Currently, this refrigerated DC directly delivers fresh food to all the stores in the neighboring region. Since direct deliveries are cost intensive, the question of setting up smaller refrigerated 'satellite' DCs arises. The basic idea is to use the economies of scale with large trucks from the central DC to the potential sub DCs and perform the direct delivery from the sub DCs to the stores (see Figure 1). A major interest for the considered company is the analysis of the trade-off between potential transportation cost savings and the additional DC cost.

Moreover, due to the government's determination to avert climate change, a series of carbon policies are under discussion. It is popular to make use of tax leverage by pricing carbon emission or use carbon capand-trade policy. If carbon policies are carried out, the carbon emission caused by transportation and inventory may be charged, where fuel is the source of carbon emission in transportation and electricity and gas are sources in inventory. Especially for fresh food, 
carbon emission also arises from refrigeration. Then we need to consider that: will the existence of a carbon policy affect decisions of companies, especially those having carbon-intensive activities like transportation and refrigeration inventory? Under carbon policies made by the government, can companies seek decisions which are optimal in different settings? We will also solve this problem for our case study.

This paper is an attempt to discuss a traditional location problem under carbon policies. It also has a contribution to a real application. The rest of the paper is organized as follows. Section 2 is the literature review. Section 3 introduces the method to determine the location and number of potential DCs and gives notations and assumptions. Section 4 is the basis of the research which illustrates compositions of costs and provides real or estimated data. The results are given and interpreted in Section 5. Section 6 puts forward decisions under carbon tax policy and carbon cap-andtrade policy. Section 7 is the conclusion.

\section{Literature review}

This paper is an attempt to discuss the number and location problem under carbon policies. As the basis, we provide a literature review concerning location problems and operation under carbon policies.

\subsection{Location problem}

Classical location problems can be in general characterized by discrete (or mixed-integer) models, network models, and plane models. They have been studied for a long time because of the importance in logistics and supply chain management and therefore many variants have been proposed (ReVelle and Eiselt [25]). A deeper insight is beyond the purpose of our case study and we restrict ourselves to the most related problems and models. A related problem and one of the most investigated and adapted mixed integer location model is the warehouse location problem. Baumol and Wolfe [3] described the warehouse location problem as a concave minimization problem and obtained a local optimum using a computational method. Balinski [2] presented a linear mixed integer model and general algorithms for solving linear (mixed) integer problems. Numerous adaptions, heuristics and exact methods had been developed over the last decades. A comprehensive overview of warehouse location problems can be found for example in Klose and Drexl [17], Melo, Nickel and Saldanha-Da-Gama [21], and Owen and Daskin [22].

A related network model to the problem is the hub location problem which is usually used to determine the number and locations of hubs or trans-shipment facilities and to allocate geographic areas/customers to them. Solving so-called hub location problems has been the subject of various works. Economies of scale achieved through consolidation of flows is usually modeled by discounting the unit costs of transportation for inter-hub flows with a discount factor $0<\alpha<1$ to reflect the consolidation of flows between hub locations. This approach has faced much criticism (e.g. Kimms [16]) and therefore some works focus on real truck cost rather than flow costs (e.g. Baumung and Gündüz [4]). For a comprehensive overview of hub location models we refer to Alamur and Bahar [1] and Campbell and O'Kelly [11]. In our work we include the aspect of real truck costs instead of flow costs. The location model investigated in this work is mostly related to the very well known multi and single Weber problem because the prospect of the company about the number, location and size of new DCs and their cost structure is vague. Further, the work in this paper is intended to analyze theoretical potential of cost savings without taking the available transport infrastructure into account. Traditionally, the multi Weber problem is to locate a given number of facilities in the Euclidean plane to minimize the transportation cost and satisfy consumers demand. The problem reduces to the single Weber problem if only one facility has to be located. Over the last decades, many heuristics (cf. Brimberg et al. [9]) and few exact methods (e.g. Rosing [27], Righini and Zaniboni [26]) have been applied. Various heuristics and metaheuristics for the multi Weber problem (e.g. variable neighborhood and tabu search) are based on the location-allocation problem (cf. Bongartz et al. [6], Brimberg and Mladenović $[7,8]$ ) and on the p-Median problem (cf. Hansen et al. [15]). Brimberg et al. [10] also considered constant opening costs for the multi Weber problem. Drezner et al. [13] used a construction heuristic to find a starting solution, applied the Delaunay triangulation to decompose the problem, and finally solved a single facility limited median problem.

We also take kind of opening costs into account, decompose our problem by dividing the considered distribution area into reasonable regions, and solve the single Weber problem afterwards for each region. Thus, we solve several single Weber problems.

\subsection{Operation under carbon policies}

Climate change has become a global issue which requires firms to attach great importance on carbon policies. Confronted with the new situations, scholars have done plenty of researches on operation under carbon policies. Benjaafar, Li and Daskin [5] made a comprehensive overview about carbon policies 
including carbon tax, carbon cap, carbon cap-and-trade and carbon cap-and-offset, and then established corresponding models which have laid a theoretical foundation for further research about operation. Chen et al. [12] tried to determine the optimal ordering quantity with the purpose of greatly cutting down carbon emission while not increasing operational cost. The classical Economic Order Quantity (EOQ) model was established considering carbon cap, carbon tax, cap-and-offset or cap-and-price policies. Toptal et al. [28] investigated on the joint-replenishment and investment on carbon emission reduction. Their research combined the traditional EOQ problem with carbon tax or carbon cap-and-trade policies and sought the optimal investment for carbon emission reduction. Konur and Schaefer [18, 19] considered the less-thantruckload (LTL) and truckload (TL) transportation situations, and aimed to reduce cost and emission caused by the activities of ordering, transportation and inventory.

One important stream of the research is focusing on transportation. More specifically, it deals with the problem of facility location, network design, distribution routing, transportation mode selection and so on. For example, Wang et al. [29] used Multiobjective Mixed Integer Programming (MMIP) to study a network design problem, and sought the balance between cost and carbon emission. The network optimization of Elhedhli and Merrick [14] contained suppliers, DCs and consumers. The carbon emission arose from the warehouse operation, the inventory, and the transportation. It was shown in their conclusion that the existence of a carbon policy can influence network design decisions. Pishvaee and Razmi [23] chose to use fuzzy multi objective programming (IFMOP) to deal with the network design problem under a carbon policy. The supply chain which Marufuzzaman et al. [20] studied produces and ships biodiesel. They were aiming to obtain the balance among transportation cost, facility cost and carbon emission cost by making optimal decisions about the location and production quantity. Ramos et al. [24] dealt with a reverse logistics network under a carbon policy, and the decision on the strategic level was about the number and location of facilities, and the decision on the operational level was about the distribution routing. Zakeri et al. [30] provided decisions about network design, flux, replenishment and inventory, and used real data to conduct the simulation. In their research, the cost and carbon emission were studied under carbon tax policy and carbon cap-and trade policy.

Based on the location model and using the real data, we tend to provide DC decisions for Company XX.
We will also consider carbon policies and study the influences of carbon policies on DC decisions.

\section{The model}

So far in Company XX, only a single refrigerated $\mathrm{DC}$ is being used to deliver fresh food to all the stores. In addition, because Company XX owns a small amount of refrigerated trucks, the distribution is gradually outsourced to the third party logistics (3PL) and the refrigerated trucks used must meet the refrigeration requirements of Company XX. Based on the current situation, we establish an optimization model to help Company XX make cost improving decisions about the number and location of additional DCs. We intend to establish a network for fresh food distribution (see Figure 1) to better serve the expanding number of stores. The established DC acts as the central DC. It receives all the fresh food supplies and makes deliveries to refrigerated sub DCs. After that, these sub DCs distribute fresh food to the stores. The number and location of sub DCs need to be determined in order to minimize the total cost including transportation cost and DC cost.

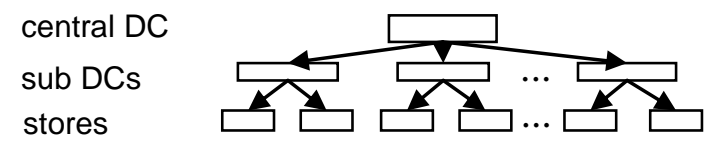

Figure 1. Fresh food distribution network

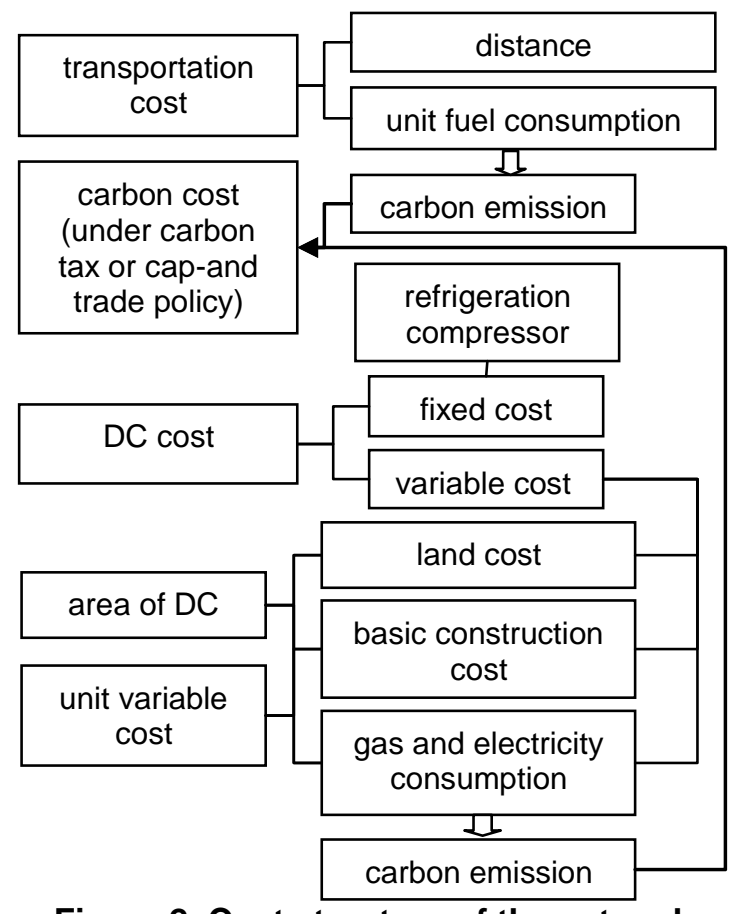

Figure 2. Cost structure of the network 
The cost structure of the distribution network is shown in Figure 2, and the total cost consists of transportation cost and DC cost in the basic setting. The transportation cost is caused by fuel consumption, which is calculated based on the number of distributions and the type of truck. There are three types of trucks to be used. Different trucks consume different amounts of fuel. DC cost consists of fixed cost and variable cost. The fixed cost is caused by the refrigeration compressor which should be installed in each DC. The variable cost consists of land cost, basic construction cost and cost of gas and electricity consumed in daily operation. Stated in another way, the sum of land cost, basic construction cost and refrigeration compressor cost is the setup cost, and the cost of gas and electricity is the operation cost. If extending to the situation under carbon policies, the carbon emission caused by fuel, gas and electricity consumption will be charged. We will consider carbon tax policy and carbon cap-and-trade policy.

We introduce the following notations related to the available data and assumptions of the model. The data contains demand per region in three categories related to the size of the delivery trucks, location of stores and central DC as well as data on the objective function described below.

\subsection{Notations}

(1) Parameters

$K$ : number of truck types (in our case $K=3$ );

$k$ : the sequence number of truck type;

$c_{k}$ : the transportation cost of type $k$ truck;

$f_{k}$ : the fuel consumption of type $k$ truck;

$P_{k}$ : the capacity of type $k$ truck;

$I$ : number of sub regions with $i$ being the sequence number of sub regions and DCs, and sub region 1 is the region which the central DC (DC 1) serves;

$J^{i}$ : number of stores in sub region $i$, where

$J_{0}^{i}=1$;

$J_{1}^{i}$ : number of stores in sub region $i$ whose demand is less than $P_{1}$;

$J_{2}^{i}$ : number of stores in sub region $i$ whose demand is between $P_{1}$ and $P_{2}$;

$J_{3}^{i}$ : number of stores in sub region $i$ whose demand is larger than $P_{2}$;

$j:$ the sequence number of stores; $d_{j}^{i}$ : demand of store $j$ in sub region $i$;

$\left(x^{1}, y^{1}\right)$ : the location of central DC;

$\left(x_{j}^{i}, y_{j}^{i}\right)$ : the location of store $j$ in sub region $i$;

$a_{d}^{i}$ : the area of sub DC $i$;

$c_{d}^{v}$ : the variable cost of a sub DC unit area;

$c_{d}^{f}$ : the fixed cost of a sub DC (the cost of refrigeration compressor);

$e_{t}:$ emission factor of transportation;

$e_{d}:$ emission factor of sub DC operation;

$t_{c}$ : carbon tax rate under carbon tax policy;

$C_{c}$ : carbon cap under cap-and-trade policy;

$p_{p}$ : carbon purchase price under cap-and-trade policy;

$p_{s}$ : carbon sell price under cap-and-trade policy;

$E^{I}$ : total carbon emission if there are $I$ sub regions;

$s_{t}^{I}$ : the transportation cost if there are $I$ sub regions;

$s_{d}^{i}:$ DC cost of sub DC $i$;

$s_{c}^{I}$ : total carbon tax if there are $I$ sub regions;

$s_{c t}^{I}$ : the carbon cost under cap-and-trade policy if there are $I$ sub regions;

$s_{s}^{I}$ : the total cost if there are $I$ sub regions (no carbon policy).

$s_{s t}^{I}$ : the total cost under carbon tax policy if there are $I$ sub regions;

$s_{s c t}^{I}$ : the total cost under cap-and-trade policy if there are $I$ sub regions.

(2) Decision variables

$\left(x^{i}, y^{i}\right)$ : the location of sub DC $i, i=2,3 \ldots I$.

\subsection{Assumptions}

(1) All the trucks are provided by 3PL, and the trucks of the same type have the same performance. The actual load does not affect the fuel consumption and carbon emission of the whole truck.

(2) There is economies-of-scale in unit transportation cost. For small-quantity distribution small-capacity trucks with higher unit transportation cost are used, while for large-quantity distribution we use large-capacity trucks to distribute between the DCs with lower unit transportation cost. 
(3) Every sub DC should be equipped with refrigeration machines to keep food fresh and every sub DC has the same unit setup cost and unit operation cost.

(4) The lifetime of a sub DC is assumed to be ten years. In addition, at the end of sub DC facilities' service life the residual value is zero.

\subsection{The objective function}

In order to reduce the computational complexity, we proceed in three steps. At first we split the domain in a finite number of regions realizable for Company $\mathrm{XX}$ (this is at most nine). Then within each region we solved the location problem considering the capacity of different types of available trucks and the given demands of each store. The objective is to minimize transportation cost as shown in Formula (1). The transportation contains the transportation between the central DC and sub DCs along with the transportation between the sub DC and the stores in its sub region. Formally, the problem is to

$$
\begin{aligned}
& \min s_{t}^{I}=\sum_{i=1}^{I} \sum_{k=1}^{K} \sum_{j=J_{k-1}^{i}}^{J_{k}^{i}} c_{k} \sqrt{\left(x^{i}-x_{j}^{i}\right)^{2}+\left(y^{i}-y_{j}^{i}\right)^{2}}+ \\
& c_{3} \sum_{i=1}^{I} \sqrt{\left(x^{1}-x^{i}\right)^{2}+\left(y^{1}-y^{i}\right)^{2}}\left[\sum_{j=1}^{J^{i}} d_{j}^{i} / P_{3}\right]
\end{aligned}
$$

s.t. $I=2,3,4,6,9$,

$$
j=1,2 \ldots J^{i},
$$

where $\lceil$.$\rceil rounds the value to the next biggest integer$ value. Large-capacity trucks are used to distribute between the center DC and sub DCs according to our assumption. In Formula (1), $c_{3}$ refers to the transportation cost of the type 3 truck and $P_{3}$ is the corresponding capacity. Since the total demand in a sub region is known, the size of sub DC and DC cost $s_{d}^{i}$ can also be computed in advance. Also, the location of each sub DC is given by the arithmetic mean of the coordinates of the stores weighted by $c_{k}$ and with a weighted influence of the central DC. The analytical Formula (1) was implemented in Matlab $\mathrm{R} 2012 \mathrm{~b}$ to determine the optimal locations. Lastly, we determine the optimal number of sub DCs which minimizes the total cost $s_{s}^{I}$ including transportation cost and DC cost as shown in Formula (2), and the number of sub DCs leading to the lowest total cost is the optimal decision. $\min s_{s}^{I}=s_{t}^{I}+\sum_{i=2}^{I}\left(a_{d}^{i} c_{d}^{v}+c_{d}^{f}\right)$

s.t. $I=2,3,4,6,9$.

Applying Formula (1) and afterwards (2) to obtain a solution is referred to as Method 1 in the remaining paper.

\section{The source data}

Part of the source data was obtained from Company XX, and the remaining data which the company could not provide was collected from websites.

\subsection{The data provided by Company XX}

The central DC is responsible for the distribution of fresh food including fruit, vegetable, seafood and other food to 476 stores. We have the

(1) Demand of each store (time span: 21.12.201527.12.2015);

(2) Location of each store (in the form of latitude and longitude, $1^{\circ} \approx 100 \mathrm{~km}$ );

(3) Information of Company XX's own refrigerated trucks (see Table 1). There are three types of trucks, and the trucks are named in the order of capacity. Transportation cost of a truck per distance is related to the truck type and fuel price. Trucks of type 1 are used for delivery quantity less than $1495 \mathrm{~kg}$; for that between $1495 \mathrm{~kg}$ and $3400 \mathrm{~kg}$, trucks of type 2 are used; for that more than $3400 \mathrm{~kg}$, trucks of type 3 are used. For the use of economies-of-scale between the central DC and sub DCs trucks of type 3 are used by assumption. Although the fuel consumption of a type 3 truck is the largest, the unit fuel consumption (per weight) of a type 3 truck is the lowest.

Table 1. Features of refrigerated trucks

\begin{tabular}{|c|c|c|c|}
\hline & Type 1 & Type 2 & Type 3 \\
\hline Brand & JAC & ISUZU & ISUZU \\
\hline Total weight $(\mathrm{kg})$ & 4325 & 7300 & 9410 \\
\hline Capacity $P_{k}(\mathrm{~kg})$ & 1495 & 3400 & 4300 \\
\hline Fuel & diesel & diesel & diesel \\
\hline $\begin{array}{c}\text { Fuel consumption } \\
\text { of the whole truck } \\
f_{k}(\mathrm{~L} / 100 \mathrm{~km})\end{array}$ & 10.3 & 15.6 & 16.5 \\
\hline
\end{tabular}

\subsection{Data obtained from websites}

For consistency reasons we use the fuel price and exchange rates from a single day (02.05.2016) and do not account for possible changes afterwards. 
4.2.1. Unit transportation cost. The fuel price is 7.01 Yuan/L. Thus, the unit transportation costs are 0.72203 Yuan $/ \mathrm{km}, 1.09356$ Yuan $/ \mathrm{km}$ and 1.15665 Yuan $/ \mathrm{km}$, for type 1, 2, and 3 truck, respectively.

4.2.2. DC cost. The DC cost consists of:

(1) Total cost of a sub DC per day

$c_{t d}^{i}$ : the total cost of a sub DC in sub region $i$ as the sum of land cost, basic construction cost, electricity and gas costs, and refrigeration compressor cost.

$s_{d}^{i}$ : the daily cost of the sub DC in sub region $i$ which is obtained from $c_{t d}^{i}$.

(2) The size of a sub DC

For computing the cost of a sub DC we have to estimate its size. The density of fresh vegetable and fruit as $230 \mathrm{~kg} / \mathrm{m}^{3}$ and with the assumption that the height of the warehouse is $3 \mathrm{~m}$ and the volume utilization ratio is $90 \%$, it is inferred that the size of each sub DC is smaller than $500 \mathrm{~m}^{2}$, which means that the sub DCs are small or medium ones.

(3) Setup cost of sub DCs

According to the latest data, the average price of industrial land in province AA was $414 \mathrm{Yuan} / \mathrm{m}^{2}$ in 2013. Considering the size of sub DCs, we assume the basic DC construction cost as $\$ 50 / \mathrm{m}^{2}$ according to the prices asked by service providers on Alibaba. Then the basic construction cost is $323.69 \mathrm{Yuan} / \mathrm{m}^{2}$. Due to inadequate information about the cost of refrigeration compressor, we set it as a variable in the scope of [5000, 50000] US Dollar ([32369, 323690] Yuan) based on the price on Alibaba.

(4) Operation cost of sub DCs caused by electricity and natural gas consumption

Refrigerated warehouses consume an average of $24.9 \mathrm{kwh}$ of electricity and $9200 \mathrm{btu}$ of natural gas per square foot per year; the electricity price for industrial usage is $0.8289 \mathrm{Yuan} / \mathrm{kwh}$; the price of natural gas is 2.86 Yuan $/ \mathrm{m}^{3}\left(1 \mathrm{kwh}=0.09 \mathrm{~m}^{3}\right.$ gas, $1 \mathrm{btu}=0.0002931$ $\mathrm{kwh}, 1$ square foot $=0.092903$ square meter). Then the cost of electricity and natural gas in a sub DC per day is about $0.6291 \mathrm{Yuan} / \mathrm{m}^{2}$.

\section{Simulation results}

We calculate the total cost for the daily operation of the distribution network, including transportation cost per day and DC cost per day. The average demand of one week is used as the actual demand per day for sampling. The optimal location of each potential DC within each sub region is obtained as the solution to the location optimization problem.
Table 2. Transportation cost per day

\begin{tabular}{|c|c|c|}
\hline Cases & $\begin{array}{c}\text { Number of } \\
\text { sub DCs }\end{array}$ & $\begin{array}{c}\text { Total transportation } \\
\text { cost (Yuan/day) }\end{array}$ \\
\hline 1 sub regions & 0 sub DC & 11558.58 \\
\hline 2 sub regions & 1 sub DCs & 5815.83 \\
\hline 3 sub regions & 2 sub DCs & 5317.81 \\
\hline 4 sub regions & 3 sub DCs & 3439.92 \\
\hline 6 sub regions & 5 sub DCs & 3256.75 \\
\hline 9 sub regions & 8 sub DCs & 3065.93 \\
\hline
\end{tabular}

As shown in Table 2, the transportation cost at eight sub DCs is the lowest, which is about $30 \%$ of the current transportation cost (no sub DC). Clearly, transportation cost decreases with increasing number of sub regions and number of sub DCs. An example of the optimal location is shown in Figure 3 for eight sub DCs. Because of the Euclidean distance we consider in weighted norm to fulfill the given demands, along with the frequent trips from the central DC to sub DCs, the location of the sub DC may deviate from its sub region.



Figure 3. Sub DCs in nine sub regions

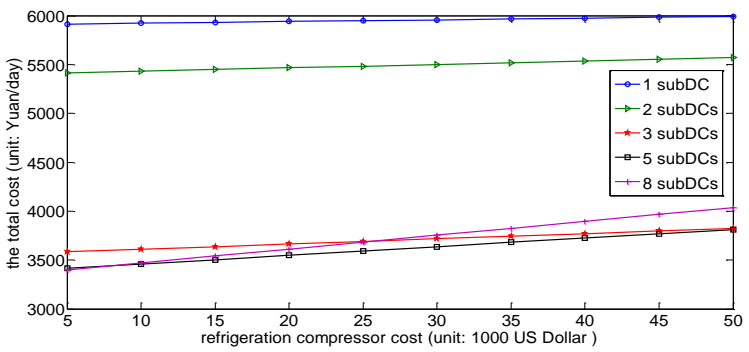

Figure 4. The total cost

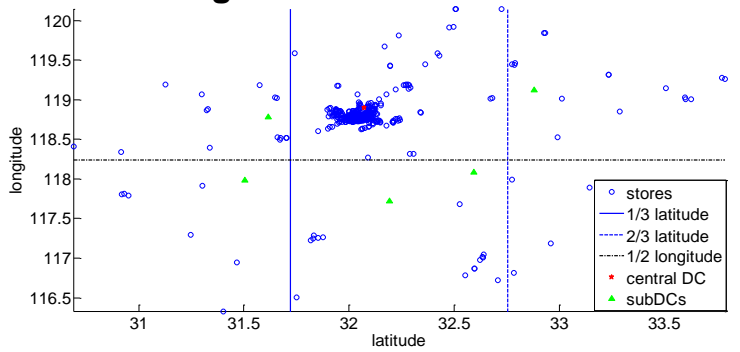

Figure 5. Sub DCs in six sub regions

Including setup and operation costs of DCs might reduce the optimal number of sub DCs because those 
costs have to be balanced against transportation costs. Obviously, higher refrigeration compressor cost leads to higher DC cost. Even so the DC cost is comparatively much lower than the transportation cost. We observe a balancing of those costs at five sub DCs. The total cost at five sub DCs is the lowest except when the refrigeration compressor is extremely cheap. The total cost including transportation cost and DC cost is depicted in Figure 4. Hereinafter the unit of total cost is Yuan/day and the unit of refrigeration compressor cost is $10^{3}$ US Dollar. The optimal locations of five sub DCs are depicted in Figure 5.

To figure out the optimization efficiency of our decision method (Method 1), we use another method (Method 2) of setting up sub DCs as comparison. Method 2 chooses the location of each sub DC as the barycenter of the coordinates of all the stores in its region. The comparison shows that neglecting transportation costs leads to higher overall costs of at most $36 \%$ (see Figure 6).

It is also depicted in Figure 7 that with more sub regions, the total cost advantage of the present method over the other one is more obvious. The comparison shows that with the present method the total costs are at most $28 \%$ lower than the other method.

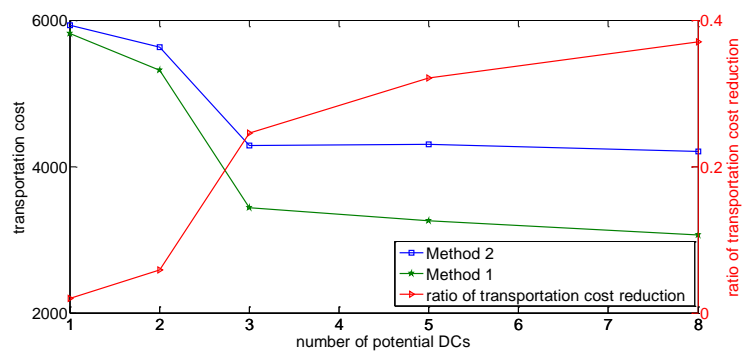

Figure 6. Comparison of transportation cost



Figure 7. Comparison of the total cost

\section{Influence of carbon policies}

In the operation of Company XX's distribution network, carbon emission is produced from activities including transportation and inventory. The trucks used by Company XX consume diesel and therefore produce 22.38 pounds of $\mathrm{CO}_{2}$ per gallon diesel. Then the carbon emission of diesel is about $2.6817 \mathrm{~kg} / \mathrm{L}$ which is denoted as $e_{t}$ in the following model. In refrigerated warehouses, $\mathrm{CO}_{2}$ is caused by electricity and natural gas consumption. According to the data of The Emissions \& Generation Resource Integrated Database (eGRID) in 2010, electricity emission factor is $6.89551 \times 10^{-4}$ metric tons $/ \mathrm{kwh}$. The average carbon coefficient of natural gas is $14.46 \mathrm{~kg} / \mathrm{mmbtu}$ according to the data of US Environmental Protection Agency (EPA) in 2013.

Refrigerated warehouses consume an average of $24.9 \mathrm{kwh}$ of electricity and $9200 \mathrm{btu}$ of natural gas per square foot per year. Knowing that $1 \mathrm{btu}=0.0002931$ kwh and 1 square foot $=0.092903$ square meter, the total emission of $0.5207 \mathrm{~kg} / \mathrm{m}^{2} /$ day in a DC is denoted as $e_{d}$ in the model.

\subsection{Under carbon tax policy}

Under a carbon tax policy, all emitted carbon should be taxed, and the carbon tax is proportional to the carbon emission. The carbon emission of the distribution network is

$$
\begin{aligned}
& E^{I}=\sum_{i=1}^{I} \sum_{k=1}^{K} \sum_{j=J_{k-1}^{i}}^{J_{k}^{i}} f_{k} e_{t} \sqrt{\left(x^{i}-x_{j}^{i}\right)^{2}+\left(y^{i}-y_{j}^{i}\right)^{2}}+\sum_{i=2}^{I} a_{d}^{i} e_{d} \\
& +\sum_{i=1}^{I} \sqrt{\left(x^{1}-x^{i}\right)^{2}+\left(y^{1}-y^{i}\right)^{2}} f_{3} e_{t}\left\lceil\sum_{j=1}^{J^{i}} d_{j}^{i} / P_{3}\right]
\end{aligned}
$$

$$
\begin{gathered}
\text { s.t. } \quad I=2,3,4,6,9, \\
j=1,2 \ldots J^{i} .
\end{gathered}
$$

Then the problem is formulated as $\min s_{s t}^{I}=s_{s}^{I}+E^{I} t_{c}$

$$
\text { s.t. } I=2,3,4,6,9 \text {. }
$$

Since China does not yet have its own carbon tax rate, we compute results for different carbon tax rates ranging from the current minimal rate of 0.013004 Yuan/kg (Japan) to the highest current rate of 1.092336 Yuan/kg (Sweden).

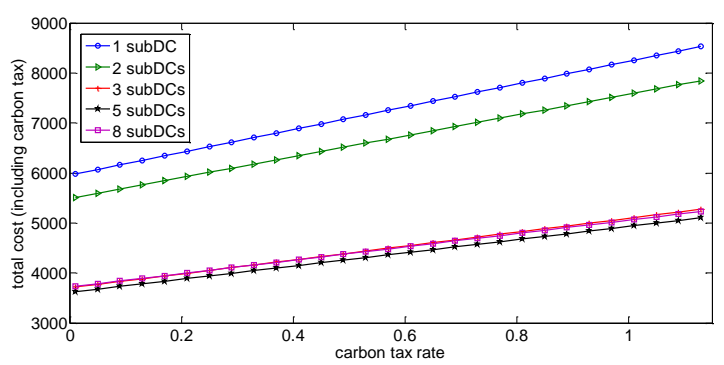

Figure 8. The total cost

Since carbon emission caused by transportation is proportional to the fuel consumption, the carbon tax 
(or carbon cost under cap-and-trade policy) caused by transportation is proportional to the transportation cost, so carbon policies will not change the location of potential sub DCs. From the results, we observe a similar qualitative behavior as in Figure 8. Setting up five sub DCs is the most economical choice in view of the total cost (here and afterwards we take the average of DC cost over refrigeration compressor cost), while setting up one sub DC is the least economical. However, the results are similar for all other carbon tax rates. With the current available prices on transportation, DC and carbon tax, aiming to minimize the total cost, it can be concluded that the influence on the decisions about establishing sub DCs is not sensitive towards carbon tax rate.

Carbon tax reflects the amount of carbon emission been produced, as we can see in Figure 9, the largest amount of carbon emission is produced at one sub DC, and the smallest amount of carbon emission is produced at five sub DCs, except when the carbon tax rate is extremely low. It means that from the perspective of curbing climate change, establishing five sub DCs is also the optimal decision.



Figure 9. The total carbon tax

Carbon tax rate has a great impact on the proportion of carbon cost in the total cost. When the carbon tax rate is $0.01 \mathrm{Yuan} / \mathrm{kg}$ (similar to Japan) carbon tax has caused $0.38 \%$ cost increase at most. When the carbon tax is 1.09 Yuan $/ \mathrm{kg}$ (similar to Sweden), the increase even reaches $41.76 \%$. With the implement of a carbon tax policy, the least carbon cost is caused at five sub DCs. That is to say, the carbon tax policy exercises the least influence over having five sub DCs than others.

\subsection{Under carbon cap-and-trade policy}

Under a carbon cap-and-trade policy, firstly carbon caps are allocated to sub DCs as the initial carbon emission permits. When the emission is more than the cap, the carbon cost paid to the trade market is proportional to the part of emission exceeding cap, or if emission is less than the cap, then the emission permits unused can be sold back to the trade market.
The objective is to minimize the total cost including carbon cost, and the problem can be formulated as

$$
\begin{aligned}
& \min s_{s c t}^{I}=s_{s}^{I}+p_{p} \max \left(E^{I}-I C_{c}, 0\right) \\
& +p_{s} \min \left(E^{I}-I C_{c}, 0\right) \\
& \text { s.t. } I=2,3,4,6,9 .
\end{aligned}
$$

By calculation, the maximum of carbon emission among sub DCs is $1358.68 \mathrm{~kg} /$ day and the minimum is $21.20 \mathrm{~kg} /$ day. So we set the carbon cap as a variable in the scope of $[0,1000] \mathrm{kg} / \mathrm{day}$. We conduct the computation using the carbon purchase price as 1 Yuan $/ \mathrm{kg}$. We also set three selling rules: Rule 1 (the purchase price is equal to the sell price), Rule 2 (the sell price is half of the purchase price), Rule 3 (the sell price is zero). They have different extents of rigidity in selling carbon permits back to the trade market.

6.2.1. Sharing carbon caps among sub DCs. In this case, sub DCs share their caps which means if the carbon emission permits of a sub DC are unused they can be transferred to other sub DCs. Under Rules 2 and 3 sharing carbon caps can reduce the carbon purchasing cost with the help of inter trade in the supermarket chain.

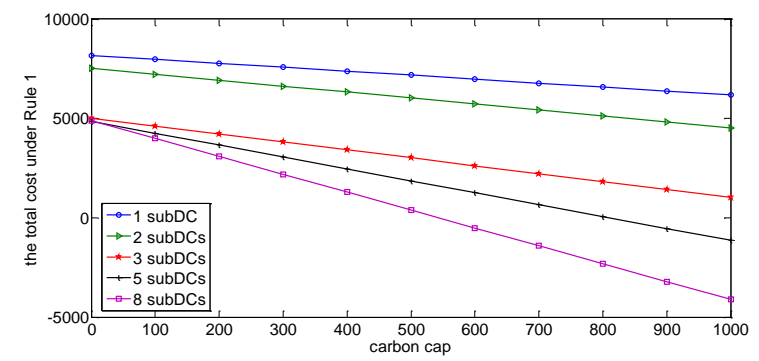

Figure 10. The total cost under Rule 1

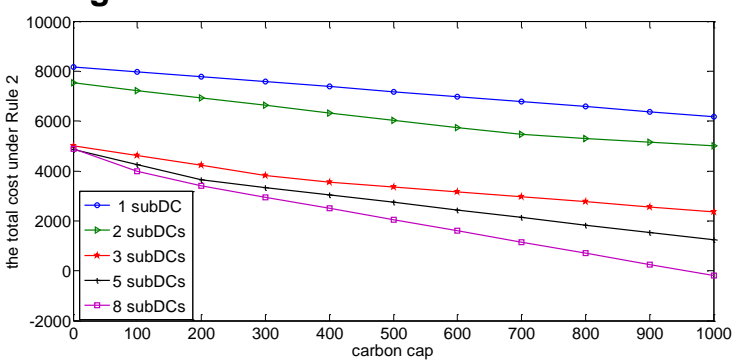

Figure 11. The total cost under Rule 2

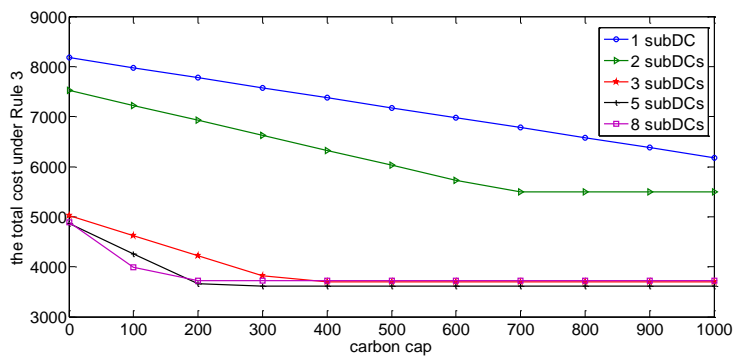

Figure 12. The total cost under Rule 3 
Observations are obtained from Figures 10-12.

(1) The total cost decreases with the increase of carbon cap and the decrease of carbon purchase price.

(2) With the more rigid selling rule, establishing five sub DCs is more likely to be the optimal decision. As shown in Figure 10, it is the optimal decision to setup eight sub DCs under Rule 1. When it is under Rule 2 (see Figure 11), the decision remains the same, while the cost advantage of having eight sub DCs over others is losing. When it comes to Rule 3 (see Figure 12), the rest of carbon permits cannot bring venture, and having five sub DCs is optimal except when the carbon cap is extremely low.

6.2.2. Sharing carbon caps is not allowed. In this case, sub DCs cannot share their caps, and if the carbon emission permits of a sub DC are unused they can only be sold back to the trade market. Under Rule 1 it makes no difference sharing carbon caps or not, because the purchase price and sell price are the same. While under Rules 2 and 3, the total cost may increase when inter trade is not allowed.

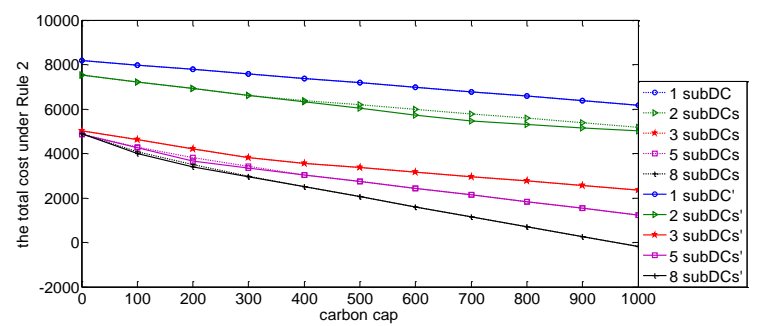

Figure 13. The comparison between the total costs (Rule 2) with or without cap sharing

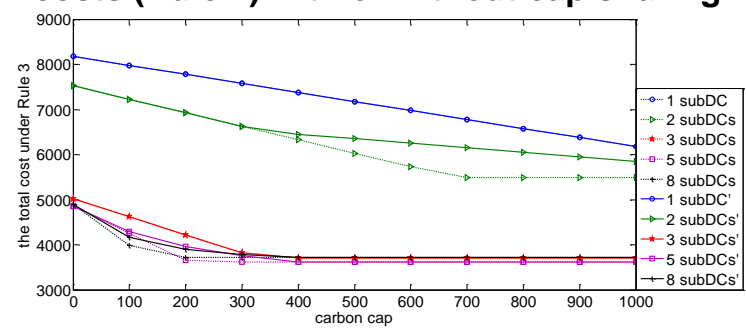

Figure 14. The comparison between the total costs (Rule 3 ) with or without cap sharing

In Figures 13-14 the dotted lines depict the total cost with cap sharing, and the full lines are about that without cap sharing. From the comparison we can see the figure patents are similar. In addition, we verify that the total cost increases without carbon cap sharing, which is more obvious under Rule 3. The maximal increase rates under Rule 3 are $11.99 \%$ at two sub DCs, $8.31 \%$ at five sub DCs, $4.95 \%$ at eight sub DCs. The increase of the total cost only occurs when the cap is relatively low. In that circumstance, the emission permits of a few sub DCs are unused and sold back to the market while the other sub DCs need to purchase with a higher price from the market.

\section{Conclusion and future research}

Carbon policies have not been carried out in China yet, while they are already on the agenda of the Chinese government. Considering that location decisions are not easy to be changed in a short time, the decision-makers should take carbon policies into account. Thus, we studied decisions of a company about location and number of sub DCs in situations of no carbon policy, carbon tax policy and carbon capand-trade policy. The results show that the carbon policy does not change the location of sub DCs, while it may influence the decision about the number of sub DCs.

(1) If carbon policies are not implemented, setting up five sub DCs is the optimal decision causing the lowest total cost among selections (one, two, three, five and eight sub DCs) we provide. Thus, the company should set up five sub DCs to cope with the distribution of fresh food, which will cut down the total cost by $68 \%$. To prove the efficiency of the optimization method, we also make comparisons between our method and another one.

(2) Under a carbon tax policy, having five sub DCs produces the least carbon emission, which also means less carbon tax or additive cost. The optimal decision about the number of sub DCs remains the same; in other words, the existence of a carbon tax policy does not affect the final decision as setting up five sub DCs.

(3) Under a carbon cap-and-trade policy, the optimal decision is dependent on the carbon selling rule (the sell price is equal to the purchase price, the sell price is half of the purchase price or the sell price is zero). With the more rigid selling rule, establishing five sub DCs is more likely to be the optimal decision. We also consider the situation that sharing carbon caps among sub DCs is not allowed, in which similar results are obtained, while there is a slight increase in the total cost.

There are still limitations in this paper. In the future research, we will take geographical conditions into consideration and emphasize more on location decision. We will also extend to a supply chain and study the behavior of its members especially regarding the carbon trading behavior under a carbon cap-andtrade policy.

\section{Acknowledgement}

This work is partially supported by the National Natural Science Foundation of China (No. 71390333), the National 
Key Technology R\&D Program of China during the 12th Five-Year Plan Period (No. 2013BAD19B05), as well as China Scholarship Council Postgraduate Scholarship Program.

\section{References}

[1] S A Alamur and B Y Kara, "Network hub location problems: The state of the art", European Journal of Operational Research, 2008, 190(1), pp. 1-21.

[2] M L Balinski, "Integer Programming: Methods, Uses, Computations", Management Science, 1965, 12, pp. 253-313. [3] W J Baumol and P Wolfe, "A warehouse-location problem", Operations Research, 1958, 6(2), pp. 252-263.

[4] M N Baumung, H I Gündüz, "Consolidation of Residual Volumes in a Parcel Service Provider's Long-Haul Transportation Network", Computational Logistics: 6th International Conference, ICCL 2015, Delft, The Netherlands, September 23-25, 2015, Proceedings, Springer International Publishing, 2015, pp. 437-450.

[5] S Benjaafar, Y Li and M Daskin, "Carbon footprint and the management of supply chains: Insights from simple models", IEEE Transactions on Automation Science and Engineering, 2013, 10(1), pp. 99-116.

[6] I Bongartz, P H Calamai, and A R Conn, "A guide projection method for $1_{p}$ norm location-allocation problems", Mathematical Programming, 1994, 66, pp. 283-312.

[7] J Brimberg and N Mladenović, "A variable neighborhood algorithm for solving the continuous location-allocation problem", Studies in Locational Analysis, 1996, 10, pp. 1-12. [8] J Brimberg and N Mladenović, "Solving the continuous location-allocation problem with tabu search", Mathematical Programming, 1996, 66, pp. 283-312.

[9] J Brimberg, P Hansen, N Mladenović, and E D Taillard, "Improvements and comparison of heuristics for solving the uncapacitated multisource Weber problem", Operations Research, 1998, 48(2), pp. 444-460.

[10] J Brimberg, N Mladenović, and S Salhi, "The MultiSource Weber Problem with Constant Opening Cost", The Journal of the Operational Research Society, 2004, 55(6), pp. 640-646.

[11] J F Campbell and M E O'Kelly, "Twenty-Five Years of Hub Location Research", Transportation Science, 2012, 46(2), pp. 153-169.

[12] X Chen, S Benjaafar, and A Elomri, "The carbonconstrained EOQ", Operations Research Letters, 2013, 41(2), pp. 172-179.

[13] Z Drezner, J Brimberg, N Mladenović, and S Salhi, "New local search methods for solving the multi-source Weber problem", Annals of Operations Research, 2015, pp. $1-23$.

[14] S Elhedhli, and R Merrick, "Green supply chain network design to reduce carbon emissions", Transportation Research Part D: Transport and Environment, 2012, 17(5), pp. 370-379.

[15] P Hansen, N Mladenović, and É Taillard, "Heuristic solution of the multisource Weber problem as a p-median problem", Operations Research Letters, 1998, 22(2-3), pp. 55-62.
[16] A Kimms, "Economies of scale in hub \& spoke network design models: We have it all wrong", Perspectives on Operations Research: Essays in Honor of Klaus Neumann, Deutscher Universitäts-Verlag, 2006, pp. 293-317.

[17] A Klose and A Drexl, "Facility location models for distribution system design", European Journal of Operational Research, 2005, 162(1), pp. 4-29.

[18] D Konur, and B Schaefer, "Integrated inventory control and transportation decisions under carbon emissions regulations: LTL vs. TL carriers", Transportation Research Part E: Logistics and Transportation Review, 2014, 68, pp. 14-38.

[19] D Konur, "Carbon constrained integrated inventory control and truckload transportation with heterogeneous freight trucks", International Journal of Production Economics, 2014, 153, pp. 268-279.

[20] M Marufuzzaman, S D Eksioglu, and Y E Huang, "Two-stage stochastic programming supply chain model for biodiesel production via wastewater treatment", Computers \& Operations Research, 2014, 49, pp. 1-17.

[21] M T Melo, S Nickel, F Saldanha-Da-Gama, "Facility location and supply chain management-A review", European Journal of Operational Research, 2009, 196(2), pp. 401-412.

[22] S H Owen and M S Daskin, "Strategic facility location: A review", European Journal of Operational Research, 1998, 111(3), pp. 423-447.

[23] M S Pishvaee, and J Razmi, "Environmental supply chain network design using multi-objective fuzzy mathematical programming", Applied Mathematical Modelling, 2012, 36(8), pp. 3433-3446.

[24] T R P Ramos, M I Gomes, and A P Barbosa-Póvoa, "Planning a sustainable reverse logistics system: Balancing costs with environmental and social concerns", Omega, 2014, 48, pp. 60-74.

[25] C S ReVelle and H A Eiselt, "Location analysis: A synthesis and survey", European Journal of Operational Research, 2005, 165(1), pp. 1-19.

[26] G Rhigini and L Zaniboni, "A branch-and-price algorithm for the multi-source Weber problem", International Journal of Operational Research, 2007, 2(2), pp. 188-207.

[27] K E Rosing, "An optimal method for solving the (generalized) multi-Weber problem", European Journal of Operational Research, 1992, 58, pp. 414-426.

[28] A Toptal, H Özlü, and D Konur, "Joint decisions on inventory replenishment and emission reduction investment under different emission regulations", International Journal of Production Research, 2014, 52(1), pp. 243-269.

[29] F Wang, X Lai, and N Shi, "A multi-objective optimization for green supply chain network design", Decision Support Systems, 2011, 51(2), pp. 262-269.

[30] A Zakeri, F Dehghanian, B Fahimnia and J Sarkis, "Carbon pricing versus emissions trading: A supply chain planning perspective", International Journal of Production Economics, 2015, 164, pp. 197-205. 